\title{
Selection of the optimal value of compressive stress in concrete under adverse external impacts
}

\author{
Anatoliy Goncharov ${ }^{*}$ \\ Moscow State University of Civil Engineering, Yaroslavskoe shosse, 26, Moscow, 129337, Russia
}

\begin{abstract}
This article reviews the effect of static and dynamic compressive stresses on the durability of reinforced concrete structures in aggressive environments. Based on the analysis of previous work and research on this issue, the author describes the main activities to be implemented in the course of works to ensure the durability of concrete and safety of reinforcement. He outlines the necessary measures to reduce the magnitude of dynamic stresses in pile driving and to ensure the healing of microdamage incurred therein. It is proved in the article that the implementation of the proposed set of measures will allow using reinforced concrete piles as supporting structures of quays in harsh climatic conditions.
\end{abstract}

\section{Introduction}

Research on durability of loaded concrete over the past 50 years $[1,2,3]$ has convincingly proved that compressive stresses acting in concrete during the entire period of operation of a structure have a significant impact on the durability of concrete and the safety of reinforcement in adverse effects of the environment. The most destructive effect on concrete is caused by alternate freezing and thawing of concrete saturated with salt solutions, or freezing of concrete in salt solutions (seawater). Along with possible reduction in the strength of concrete, the corrosion of reinforcement and the development of creep deformations are accelerated. For example, in the variable water level zone in the Barents Sea (fluctuation amplitude $\pm 2 \mathrm{~m}$ twice a day) concrete berthing structures annually experience more than 300 cycles of alternate freezing and thawing with saturation with sea water. This fact still prevents the use of reinforced concrete piles in the construction of quays.

The impact of the magnitude of stress on the resistance of concrete to external factors is conditional on changes in the pore structure of concrete induced by load. On this basis, O. Berg has proposed the calculation of structures in terms of combined action of the load and

\footnotetext{
* Corresponding author: ttg38@mail.ru
} 
adverse environmental factors [1]. He determined the microcracking boundary $\mathrm{R}^{\circ} \mathrm{t}$ under compressive stresses for various types of concrete.

Studies of the permeability of concrete by the electrical conductivity method [4] under compressive loading have shown that in the direction perpendicular to the action of the force, the permeability decreases as the stresses increase to the boundary $\mathrm{R}^{\circ} \mathrm{t}$. With further growth of stress the permeability increases and at values $\sigma=0.4-0.6 \mathrm{Rb}$ becomes higher than its initial value. Similar results have been obtained in the studies of water resistance of concrete [3].

Research on frost resistance of concrete loaded with compression has shown that the frost resistance of concrete changes similarly to the change in its permeability, increasing with the growing stress up to the boundary $\mathrm{R}^{\circ} \mathrm{t}$ and decreasing with further growth in stress $[2]$.

\section{Materials and methods}

The role of changes in the permeability of concrete in terms of its durability was also tested when concrete was exposed to an aggressive sulfate solution, as well as in the studies of the preservation of reinforcement in concrete. After hardening in normal conditions, $4 \times 4 \times 16$ $\mathrm{cm}$ samples were saturated with fresh water or a $5 \% \mathrm{Na}_{2} \mathrm{SO}_{4}$ solution and placed in loading devices in polyethylene bags. At a constant load ranging from 0.2 to $0.7 \mathrm{Rb}$, the samples were kept for 3 years. Some of the samples had a reinforcing bar in the middle part. After curing and unloading, the change in weight and dynamic modulus of elasticity were measured in the samples and then the prism strength was determined. In addition, the chemical analysis determined the content of $\mathrm{SO}_{3}$ in relation to the amount of cement. The tests performed showed that the strength of concrete kept in fresh water under load was stable up to the value of $\sigma=0.4 \mathrm{Rb}$, while at $\sigma=0.5 \mathrm{Rb}$ it became somewhat higher and at $\sigma=0.7 \mathrm{Rb}$ it decreased considerably. It can be assumed that when concrete is kept in fresh water, the load of up to $\sigma=0.6 \mathrm{Rb}$ does not cause any decrease in the strength of concrete, despite the occurrence of microfractures, which obviously cause additional hydration of cement in the presence of water.

The strength of concrete stored under load in a $\mathrm{Na}_{2} \mathrm{SO}_{4}$ solution was the highest at $\sigma=$ 0.2-0.3 Rb. In unstressed concrete and at $\sigma>0.4 \mathrm{Rb}$ the strength of concrete decreased.

Comparison of the strength of loaded concrete samples kept in a $\mathrm{Na}_{2} \mathrm{SO}_{4}$ solution and in water showed that at $\sigma=0.2-0.3 \mathrm{Rb}$ the concrete has the highest sulfate resistance. At stresses less or greater than these values, sulfate resistance is much lower.

Data on the accumulation of $\mathrm{SO}_{3}$ in concrete show that with increasing loads up to $\sigma=$ $0.4 \mathrm{Rb}$ the content of $\mathrm{SO}_{3}$ decreases, and increases with further growth in load and reaches its maximum at $\sigma=0.6-0.7 \mathrm{Rb}$.

Data on weight change of samples kept under load show that the weight gain when concrete is kept in fresh water is independent of the load level and is markedly inferior to the weight gain when it is kept in a $\mathrm{Na}_{2} \mathrm{SO}_{4}$ solution. When concrete was kept in this solution, the smallest weight gain was in samples with a load of $\sigma=0.3-0.5 \mathrm{Rb}$, while the largest weight gain was in samples without any load. The observed slight weight gains at $\sigma$ $=0.6 \mathrm{Rb}$ and especially at $\sigma=0.7 \mathrm{Rb}$ were found to be unreliable, since these samples exhibited a partial crumbling of concrete in their ribs.

The conducted studies showed that sulfate resistance of concrete was at its maximum at the optimum compressive load in the range of $\sigma=0.2-0.4 \mathrm{Rb}$. More significant loads lead to a lower sulfate resistance.

The impact of the stress state on the safety of reinforcement was studied using the same loading devices. The prisms were reinforced along the axis by a $5 \mathrm{~mm} \emptyset$ rod of class A240 
steel (st.3). When kept under load, the prisms were immersed in a 3\% NaCL solution for one-third of their height.

The rods were removed from the prisms 6 and 12 months after being kept under loads ranging from 0 to $0.8 \mathrm{Rb}$, and their degree of corrosion was determined. After a 6-month test, the least corrosion of the rods was detected in the samples loaded at $0.4-0.5 \mathrm{Rb}$, while the greatest corrosion was at $\sigma=0-0.2$ and $0.8 \mathrm{Rb}$. After 12 months, the best preservation of rods was observed in the samples at $\sigma=0.4 \mathrm{Rb}$.

Some samples after short-term loading at $0.6 \mathrm{Rb}$ were unloaded to $0.3 \mathrm{Rb}$ and kept under load for 12 months. The degree of corrosion in this case was much lower than at a constant load of $0.6 \mathrm{Rb}$. This indicates that the degree of concrete softening is most important for the corrosion process, depending on the size and duration of the load.

The conducted experiments confirmed that the impact of the concrete stress state on the rate of corrosion of reinforcement was similar to its effect on freeze-thaw resistance and corrosion of concrete under the influence of corrosive environment. Minimum corrosion is observed at loads close to $R_{\mathrm{T}}^{0}$. When loads exceed $0.5-0.6 \mathrm{Rb}$, the corrosion of reinforcement is more intense than in unloaded concrete.

\section{Results and discussion}

Previous studies [2] showed that the effect of stress state on concrete freeze-thaw resistance depended on the initial concrete structure, in particular, on the presence of special additives that change the pore structure.

To check whether these additives influence the rate of reinforcement corrosion in loaded concrete, additional studies were carried out according to the above method. 3 sample batches were simultaneously tested. The concretes in these batches were quite similar in strength, but different in pore structure. The concrete from batch 1 did not contain additives. The concrete from batch 2 contained a complex additive SNV + SDB (air entrainment + plasticization), the concrete from batch 3 - a complex additive GKZH-94 + $\mathrm{SDB}$ (gas formation + plasticization). The samples were loaded to stresses of $0.25-0.3 \mathrm{Rb}$ and $0.7 \mathrm{Rb}$. The corrosion rate in rods was determined by weight loss after they had been removed from the concrete and the corrosion products had been eliminated. The results of studies are specified in tables 1 and 2.

Table 1. Loss of weight in rods after testing in a corrosive environment.

\begin{tabular}{|l|l|l|l|}
\hline \multirow{2}{*}{ Concrete additives } & \multicolumn{3}{|l|}{ Weight loss } \\
\cline { 2 - 4 } & $\sigma=0$ & $\sigma=0,25-0,3 \mathrm{Rb}$ & $\sigma=0,7 \mathrm{Rb}$ \\
\hline \multirow{2}{*}{ SNV+SDB } & 0,04 & 0,03 & 0,07 \\
GKZH-94+SDB & 0,03 & 0,02 & 0,03 \\
\hline
\end{tabular}

Table 2. Concrete strength after testing in a corrosive environment.

\begin{tabular}{|l|l|l|l|l|}
\hline $\begin{array}{l}\text { Concrete } \\
\text { additives }\end{array}$ & $\begin{array}{l}\text { Concrete } \\
\text { strength before } \\
\text { testing, MPa }\end{array}$ & \multicolumn{5}{|l|}{ Concrete strength after load tests: } \\
& & \multicolumn{5}{|l|}{} \\
\cline { 3 - 5 } & & $\sigma=0$ & $\sigma=0,25-0,3 \mathrm{Rb}$ & $\sigma=0,7 \mathrm{Rb}$ \\
\hline- & 29,5 & 30,6 & 32,9 & 30,6 \\
SNV+SDB & 27,2 & 31,6 & 32,7 & 30,6 \\
GKZH-94+SDB & 32,2 & 33,2 & 33,4 & 26,5 \\
\hline
\end{tabular}


It can be seen that the type of dependence of corrosion rate on the stress rate in all three batches is similar to the type obtained in the first test. The minimum corrosion is observed at stresses close to $R_{\mathrm{T}}^{0}$.

The use of complex additive SNV + SDB with sufficient air entrainment in the concrete mixture reduced the effect of stress rate on the corrosion rate. The use of gas-forming agent GKZH-94 significantly increased the protective properties of concrete in the area with low stresses (up to $R_{\mathrm{T}}^{0}$ ). This means that the additives used to increase the freeze-thaw resistance of concrete reduce the sensitivity of concrete to compressive stress and improve concrete protective properties in relation to reinforcement.

Since the most severe requirements for concrete resistance during alternating freezing and thawing in seawater are imposed on the supporting structures of quays in the northern seas that are situated in the variable water level zone, the effect of dynamic stresses during pile sinking by impact on the durability of these supporting structures was considered.

Dynamic stresses during pile driving sometimes exceed the ultimate strength of concrete and may destroy the pile heads $[5 ; 6 ; 7,8,9]$

The performed calculations of values of dynamic stresses, that are present in piles when modern hammers are used, show that these values remain close to the ultimate strength of concrete, and on many construction sites the pile heads are destroyed during driving. The performed ultrasonic measurements before and after pile driving show that in most cases the concrete in piles gets significant microcracks, which subsequently leads to piles damaging. $[10 ; 11 ; 12 ; 13]$

Currently, the single-acting hydraulic hammers are used more often. With them, it is possible to flexibly change the drop height of the striking part and, therefore, regulate the level of dynamic stresses that arise during driving. It became possible to use hammers with a striking part that weighs 3-5 times more than the pile, with drop height significantly limited (up to $400 \mathrm{~mm}$ ). This makes it possible to significantly increase the duration of impact pulse and ensure effective pile sinking with a decrease of dynamic stresses and a fewer number of impacts (with a higher design final set). However, the existing possibilities of reducing the stress level are hardly ever used.

The rate of reinforcement prestressing in driven piles and a higher compressive strength grade of concrete are the reserve for reducing the damage rate of piles during driving. When referring to the piles used abroad, the absolute concrete stresses arising from reinforcement prestressing are slightly lower than in our country, but the design concrete strength is 1.5-1.8 times higher, and, therefore, the relative concrete strength is much lower. For example, in the US, the stresses in the concrete of piles that arise from reinforcement prestressing do not exceed 0.227 of prism strength. For comparison, in the hydraulic piles used in our Azov-Black Sea basin, these stresses are 0.35-0.6 from concrete prism strength.

The maximum value of dynamic stress arising during pile driving is also one of the key factors that influence the reinforcement corrosion rate.

In $[14,15]$ the main factors influencing the reinforcement corrosion rate are listed and the requirements for limiting the dynamic stresses arising during driving are specified. However, when using piles for quays in the northern seas, additional measures are required to ensure reliable protection of reinforcement against corrosion in the variable water level zone.

It is known that an intensive process of healing of microdamages in concrete follows the dynamic loadings if there is no corrosive environment [15], and the concrete structure is restored within a period of max. 15 days. At the same time, the formation of concrete structure with better protective properties compared to the original structure is possible. During the construction of maritime hydraulics, the piles are driven in contact with seawater, and the corrosion of reinforcement in the variable water level zone is sometimes noticed immediately after pile driving. 
In this case, the most effective way to protect the reinforcement from corrosion is to color (coat) the pile section that gets into the variable water level zone during driving, with a waterproof compound. The compound must last min. 15 days. The total height of protected area should be min. 3-4 meters with a constant water level (1.5 m above and $2 \mathrm{~m}$ below the water level). In the intertidal zone, for example, in the Kola Bay (Barents Sea), the height of protected area should be 5-6 m, respectively.

During the construction of quay in Korsakov (Sakhalin Island), the piles were coated with bitumen, and this type of protection showed high efficiency. The performed potentiometric measurements showed significantly less depassivation of the reinforcement in the coated piles.

Based on the above, it is possible to determine the main requirements that must be fulfilled during pile sinking by impact in contact with a corrosive environment:

- The compressive strength grade of concrete for driven piles must be not lower than B40

- It is necessary to exclude reinforcement prestressing

- When choosing a hammer for pile sinking, it is necessary to indicate the drop height of the striking part (according to specifications) based on the condition of limiting the dynamic stresses arising during driving

- The pile section that gets into the variable water level zone during driving must be protected with a waterproof compound that can last min. 15 days

- The stresses appearing in the concrete of piles after the commissioning of structure must not exceed the boundary of microcracking $R_{\mathrm{T}}^{0}$.

\section{Conclusion}

The fulfillment of the above requirements will ensure the integrity of piles during driving, prevent reinforcement corrosion and significantly increase the durability of piles driven by impact.

The possibility of using reinforced concrete piles during the construction of quays in the Barents Sea was confirmed by field tests. $10 \times 10 \times 40 \mathrm{~cm}$ samples (material: concrete of high freeze-thaw resistance, load range: from 0 to $0.4 \mathrm{Rb}$ ) spent 5 years in the variable water level zone in the Kola Bay. At the same time, a slight increase in strength was noticed in samples loaded up to $0.3 \mathrm{Rb}$.

\section{References}

1. Berg O. On the limit state of reinforced concrete structures regarding the durability of concrete. Journal "Concrete and reinforced concrete", No. 11, 1964.

2. Goncharov A. How the stress state influences freeze-thaw resistance of concrete in the structures of marine transport facilities. Ph.D. thesis in Engineering Science. M. 1970.

3. Lavrinovich E. Dependence of concrete water resistance on the stress state. Journal "Hydraulic engineering" No. 4, 1957.

4. Gladkov V., Goncharov A., Egorycheva T. How compressive stresses influence the durability of concrete and reinforced concrete. Writings of Central scientific research institute of construction "Issues concerning the durability of concrete in transport facilities", M. 1979, pp. 17-19.

5. Gladkov V., Goncharov A. Recommendations for increasing the durability of prestressed reinforced concrete piles for marine facilities. Writings of Central scientific research institute of construction, M. 1970, pp. 23-27. 
6. Gladkov V., Goncharov A. Study on durability of reinforced concrete piles. Writing of Central scientific research institute of construction No. 78, "Application of reinforced concrete structures in harsh climatic conditions", 1974, pp. 112-117.

7. Goncharov A., Veselov A. Effect of parameters of sinking of reinforced concrete piles on subsequent freeze-thaw resistance of concrete. Writings of the $2^{\text {nd }}$ alignment meeting "The technology of construction of pile foundations", Vladivostok, 1988, pp. 34-36.

8. Goncharov A., Al Hamawi M. Effect of parameters of sinking of reinforced concrete piles on the subsequent integrity of steel reinforcement. Proceedings of the All-Union conference "Current issues in construction", Voronezh, 1987, pp. 76-79.

9. Goncharov A. Limitation of dynamic stresses during pile driving. Proceedings of the scientific and technical conference of the Institute of Construction and Architecture (Moscow State University of Civil Engineering), M, 2010, pp. 190-192.

10. Romanovskiy D., Zinoviev V. Study on microcracking of concrete during repeated cyclic loading and unloading using the ultrasonic pulse velocity method. $3^{\text {rd }}$ All-Russian ( $2^{\text {nd }}$ International) conference on concrete and reinforced concrete. Volume 1, pp. 94106, M., 2014.

11. Selyaev V., Novichkov P., Novichkova E., Kimyaeva E. Stress state of concrete due to reinforcement corrosion. The materials of conference "Durability of building materials, products and structures", Mordovian State University (Saransk), pp. 127-135.

12. Migunov V., Ovchinnikov I., Shamshina K. Methodology and results of experimental electrochemical studies carried out on direct models of reinforced concrete elements: the effect of variable load on reinforcement corrosion in design transversal concrete cracks. Online journal "Science studies", No. 4, 2015, p. 86.

13. Migunov V., Shamshina K. Methodology and results of long-term experimental tests of direct models of reinforced concrete elements intended for studying the effect of variable and constant loads (on exposure to a liquid chloride-containing environment) on the kinetics of electrochemical and physical characteristics of reinforcement corrosion in transversal cracks in the protective concrete layer. Collected papers of the $15^{\text {th }}$ international scientific and technical conference (Penza), 2015, pp. 146-149.

14. Goncharov A. Corrosion of valves in precast piles. Conference FarEastCon, 2017, p. 14-17

15. Goncharov A. Ensuring the durability of hydraulic piles driven by impact. Journal NGS No. 10, 2018, pp. 89-94. 